Journal of Al-Azhar University Engineering Sector

Vol.15, No. 57, October, 2020, 1157-1168

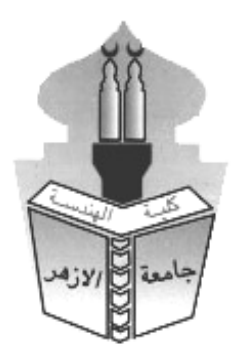

\title{
NUMERICAL INVESTIGATION OF HEAT TRANSFER AND PRESSURE DROP OF CROSS-FLOW WOVEN WIRE MESH HEAT EXCHANGER
}

\author{
Eslam Usama*, Nabil Abd el Aziz, Walid aboelsoud, and Ahmed Mohammed \\ Mechanical power Engineering Department, Faculty of Engineering, Ain Shams University, \\ Cairo, Egypt. \\ *Corresponding Author E-mail: eslamusama2015@gmail.com
}

\begin{abstract}
:
In this paper, the insertion effect of a woven wire mesh to cross flow heat exchanger will be studied under steady state laminar flow conditions. 3-D numerical model was developed for the bare heat exchanger and the other wire mesh modules. The mesh wire diameter is $2.5 \mathrm{~mm}$, porosity of 0.75 , permeability of $10^{-10}$ and layer-to-layer spacings of $(3,5,10,15,20$ and $25 \mathrm{~mm})$. Air flows with velocity range up to $3.5 \mathrm{~cm} / \mathrm{s}$ through rectangular duct of $50 \mathrm{~cm}$ X $25 \mathrm{~cm}$ with inlet temperature of $25^{\circ} \mathrm{C}$ before it is heated with corrugated water tube $(19 \mathrm{~mm}$ in diameter) with hot water inlet velocity of $1 \mathrm{~m} / \mathrm{s}$ and temperature of $50{ }^{\circ} \mathrm{C}$. The thermal and hydraulic performance were evaluated. Results showed that an enhancement in overall heat transfer coefficient was achieved of $250 \%$ for the $3 \mathrm{~mm}$ spaced module while the air pressure drop increases significantly.
\end{abstract}

KEYWORDS: Cross Flow Heat Exchanger, Woven Wire Mesh, Porous Materials, Laminar Flow, and Single Row.

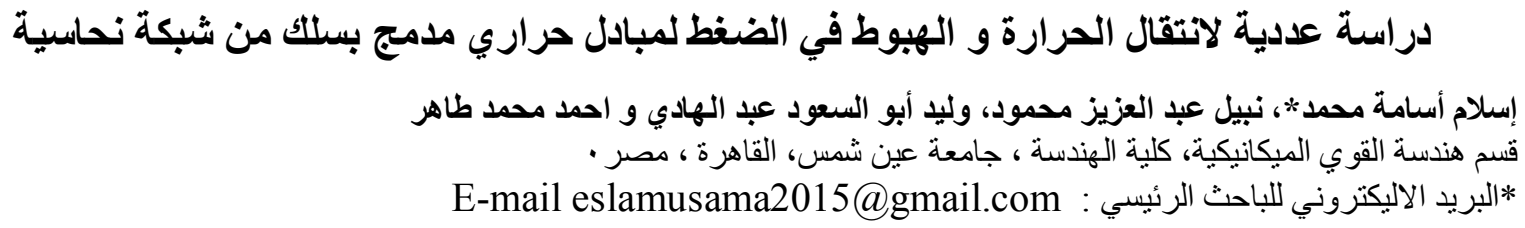

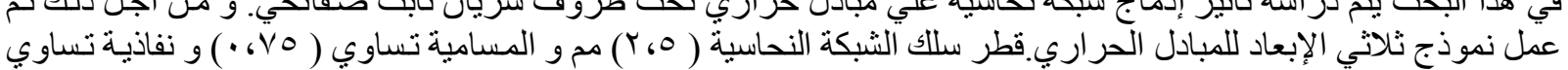

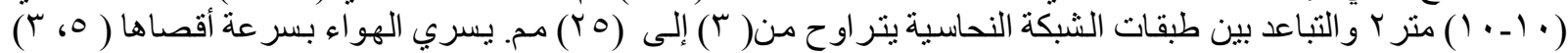

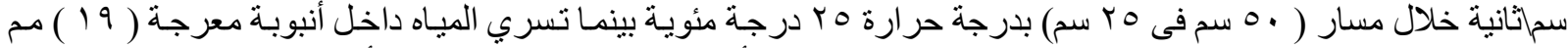

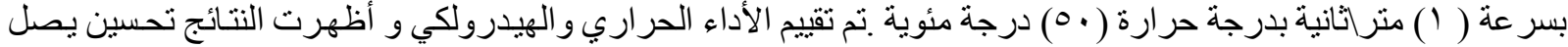

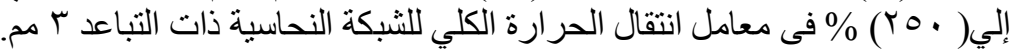

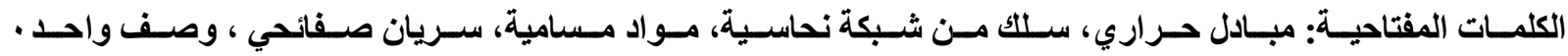




\section{Nomenclature}

$\mathrm{A}_{\text {in }} \quad$ Inside tube surface area $\left[\mathrm{m}^{2}\right]$

$\mathrm{A}_{\text {out }} \quad$ Outer tube surface area $\left[\mathrm{m}^{2}\right]$

$\mathrm{A}_{\mathrm{c}} \quad$ Cross-sectional area of flow $\left[\mathrm{m}^{2}\right]$

$\mathrm{U} \quad$ Overall heat transfer coefficient $\left[\mathrm{W} / \mathrm{m}^{2} \mathrm{~K}\right]$

$\mathrm{C}_{\mathrm{p}} \quad$ Specific heat at constant pressure $[\mathrm{J} / \mathrm{kg} \mathrm{K}]$

$\mathrm{D}_{\mathrm{h}} \quad$ Hydraulic diameter $=4 \mathrm{~A}_{\mathrm{c}} / \mathrm{P}_{\mathrm{t}}[\mathrm{m}]$

$\mathrm{D}_{\text {out }} \quad$ Tube outside diameter [m]

$\mathrm{S} \quad$ Spacing between wire mesh layers [mm]

W Wire mesh width [mm]

$\mathrm{h}_{\mathrm{o}} \quad$ Outer convection heat transfer coefficient $\left[\mathrm{W} / \mathrm{m}^{2}\right.$

$\mathrm{K}]$

$\mathrm{h}_{\text {in }} \quad$ Tube inside heat transfer coefficient $\left[\mathrm{W} / \mathrm{m}^{2} \mathrm{~K}\right]$

$Q \quad$ Hot water heat transfer rate $[\mathrm{W}]$

$\mathrm{K}_{\text {air }} \quad$ Air Thermal conductivity [W/m K]

$\mathrm{K}_{\mathrm{s}} \quad$ Solid Thermal conductivity [W/m K]

$l_{\mathrm{P}} \quad$ Copper pipe length $[\mathrm{m}]$

$\dot{\mathrm{m}} \quad$ Mass flow rate $[\mathrm{kg} / \mathrm{s}]$

$\mathrm{P}_{\mathrm{t}} \quad$ Wetted perimeter $[\mathrm{m}]$

$\Delta \mathrm{P} \quad$ Air pressure drop across heat exchanger module $[\mathrm{Pa}]$

$\mathrm{T} \quad$ Temperature $\left[{ }^{\circ} \mathrm{C}\right]$

$k \quad$ turbulent kinetic energy

$\mathrm{U} \quad$ Overall heat transfer coefficient $\left[\mathrm{W} / \mathrm{m}^{2} \mathrm{~K}\right]$

$\Delta \mathrm{T}_{\mathrm{LM}}$
$\mathrm{V}_{\text {avg,air }}$

Average air velocity in the free crosssectional area of the air duct $[\mathrm{m} / \mathrm{s}]$

F Correction Factor

$\mathrm{Re}_{\mathrm{Dh}} \quad$ Reynold's number based on Duct hydraulic diameter and air velocity

k Permeability $\left[\mathrm{m}^{2}\right]$

$\mathrm{F} \quad$ Correction Factor

$\sigma_{\mathrm{k}}, \sigma_{\varepsilon} \quad \mathrm{k}-\varepsilon$ turbulence model constants for $\mathrm{k}$ and $\varepsilon$

$\varepsilon \quad$ Porosity

$v \quad$ Kinematic viscosity $\left[\mathrm{m}^{2} / \mathrm{s}\right]$

$\mu \quad$ Dynamic viscosity [N.s $/ \mathrm{m}^{2}$ ]

$\rho \quad$ Density $[\mathrm{kg} / \mathrm{m} 3]$

$\mu_{\mathrm{T}} \quad$ turbulent viscosity N.s $\left./ \mathrm{m}^{2}\right]$

Subscript 
Reynolds number due to the presence of the mini-fins as compared to the smooth channels. (Dogan \& Sivrioglu, 2012) performed an experimental and numerical investigation on the effects of clearance gap on mixed convection heat transfer from array of fins in a horizontal channel. The fluid velocity entering the horizontal channel was varied between $(0.02$ up to $0.023 \mathrm{~m} / \mathrm{s})$ which makes the flow in the laminar regime. The results show that the heat transfer rate increases with the decrease in the clearance gap. (Kewalramani, Hedau, Saha, \& Agrawal, 2019) performed an experimental and numerical study to evaluate the hydraulic and thermal performance of elliptical pin fin micro heat sink applied with constant heat flux from the bottom. The fluid flow and heat transfer for micro elliptical shaped pin fin heat sink is studied numerically and experimentally in this study. Results showed that the hydraulic and thermal performance of micro pin fin heat sinks is dependent on the porosity and aspect ratio of the micro pin fin.

(El Maakoul, El Metoui, Abdellah, Saadeddine, \& Meziane, 2017) numerically investigated the thermohydraulic performance of air to water double pipe heat exchanger with helical fins. Results showed that for the same tube length, helical fins have about 3\%-24\% heat transfer surface area higher than longitudinal fins. Both arrangements of heat exchangers the same weight. For the same mass flow rate ,tube length and pumping power the heat transfer rate with helical fins is higher than that with longitudinal fins. (Huisseune, T'Joen, Brodeoux, Debaets, \& De Paepe, 2010) conducted an experimental study to evaluate the thermohydraulic performance a single row heat exchanger with helical fins tubes. The heat transfer rate and flow friction factor correlations are determined. The transversal pipe pitch was parametrically varied. The heat transfer rate correlation can predict $95 \%$ of the data within mean deviation of $4.49 \%$. (Dong, Chen, Zhang, \& $\mathrm{Hu}, 2010)$ carried out an experimental and numerical study to evaluate the thermohydraulic performance of wavy fin and flat tube heat exchangers. The study showed three numerical simulations and experimental investigation of air flow and heat transfer characteristics over the wavy fin heat exchanger. The experimental results show that, For the range of Re of air (from1000 to 5500), the standard k- $\varepsilon$ mode (SST) is more suitable to simulate the air flow and heat transfer of wavy fin. On the other side the porous media inserts such that metal foams, wire mesh screens and lattice frame materials are promising candidates that could achieve enhancement higher than fins. Various experimental and numerical studies are performed to evaluate the thermal behavior of metal foam heat exchangers.

(Mahajan, 2001) conducted an experimental study upon high porosity metal foams. The study presents the analytical correlations and experimental data for the effective thermal conductivity of such porous media. The study also presents results on "pool" boiling of Fluor inert fluids in such foams. (Angirasa, 2002) conducted an experimental study to investigate forced convection heat transfer with two aluminum metallic fibrous materials having different porosities of $0.93 \&$ 0.97 . The study tested the effectiveness of metal foams heat exchangers. Results show that the tested patterns with the lower porosity have lower thermal resistance and higher heat transfer rates.

(Lu, Zhao, \& Tassou, 2006) performed an analytical study to evaluate both thermal and hydraulic performance of high porosity open-cell metal-foam filled heat exchangers. The enhancement in the thermal performance is 40 times higher than the smooth pipes but the pressure drop will be also higher. (Mancin, Zilio, Diani, \& Rossetto, 2012) studied, through experimentation, the thermo-hydraulic performance of five different copper foam samples with different pore densities of $(5,10,20$ and $40 \mathrm{PPI})$, and different porosities varying between 0.905 and 0.934 . Results showed that $\mathrm{Cu}-5-6.7$ sample appears to have the best performance on the other hand The results of the experiment show that the $\mathrm{Cu}-10-9.5$ copper foam sample can be considered a suitable and viable solution for the design of innovative thermal management solutions for electronic cooling applications. (Kamath, Balaji, \& Venkateshan, 2013) showed through experiment the effect of thermal conductivity on heat transfer and pressure drop in a vertical channel embedded with aluminum and copper foams of high porosity. Copper foams of porosity of 0.87 and aluminum foams of porosity 0.95 gave the same heat transfer performance for the same velocity range and heat flux condition. (Hwang, Hwang, Yeh, \& Chao, 2002) conducted an 
experimental study to measure convective heat transfer and friction factor for flow across aluminum foams for air flow through rectangular channel. Results show that both the friction factor and the volumetric heat transfer coefficient increase with decreasing the foam porosity at a fixed Reynolds number. In addition, the aluminum foam of $(\varepsilon=0.8)$ has the best thermal performance under the same pumping power constraint among the three aluminum foams investigated.

(Fugmann, Tahir, \& Schnabel, 2015) conducted both numerical and experimental study to evaluate the thermohydraulic performance of woven wire gas-To-liquid heat exchanger An enhancement in the convective heat transfer coefficient was achieved with using woven wire mesh. Correlations for predicting the friction factor and Nusselt number were derived using measurement data. (Dyga \& Płaczek, 2010) showed by experimentation, the hydrothermal performance of heat exchangers with wire mesh packing. Results showed that differences between heat fluxes (in an empty and packed channel) compensates for the higher demand for energy to pump the gas through wire mesh packing. In the circumstances of this research the enhancement from using wire mesh packing up to $40 \%$.

\section{NUMERICAL METHOD}

\section{1.physical model}

Figure 1 shows the wire mesh heat exchanger. As shown in the figure, the horizontal rectangular duct having cross sectional area of $50 \mathrm{~cm} \times 25 \mathrm{~cm}$ and $120 \mathrm{~cm}$ long. A corrugated pipe having a diameter of $19.5 \mathrm{~mm}$ is installed at the middle of the duct. The wire diameter of woven wire mesh is $2.5 \mathrm{~mm}$ and width of $40 \mathrm{~mm}$ with porosity of 0.75 and permeability of $10^{-10} \mathrm{~m}^{2}$

Moreover, the following assumptions are considered for calculation in this paper:

(1) Copper wire mesh used in this paper are assumed to be isotropic and homogeneous with uniform porosity and permeability.

(2) The thermo-physical parameters of gas and copper are regarded to be temperature independent.

(3) Heat transfer owing to radiation and natural convection is negligible.

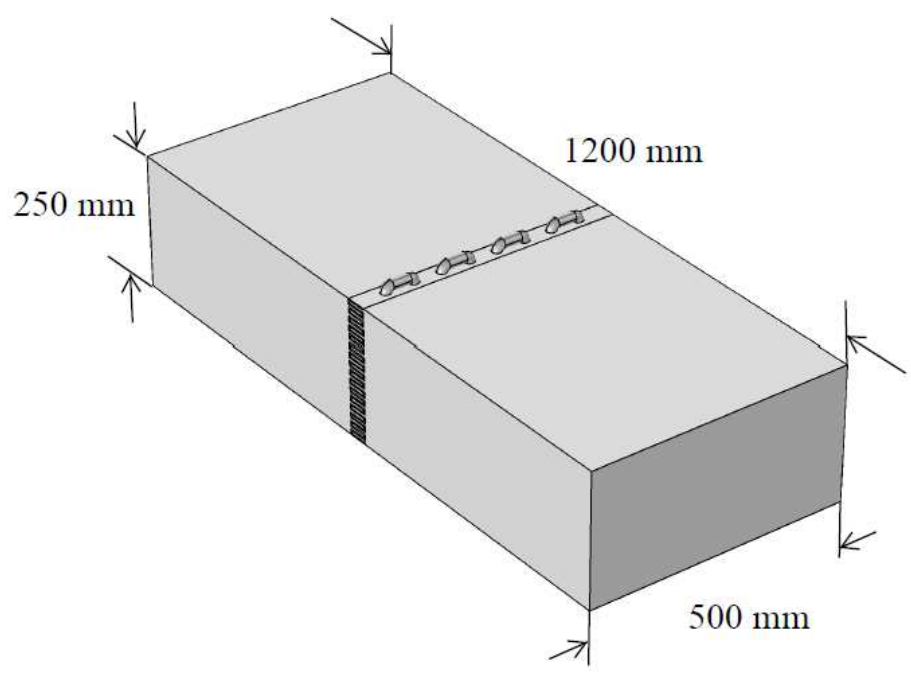

(a)

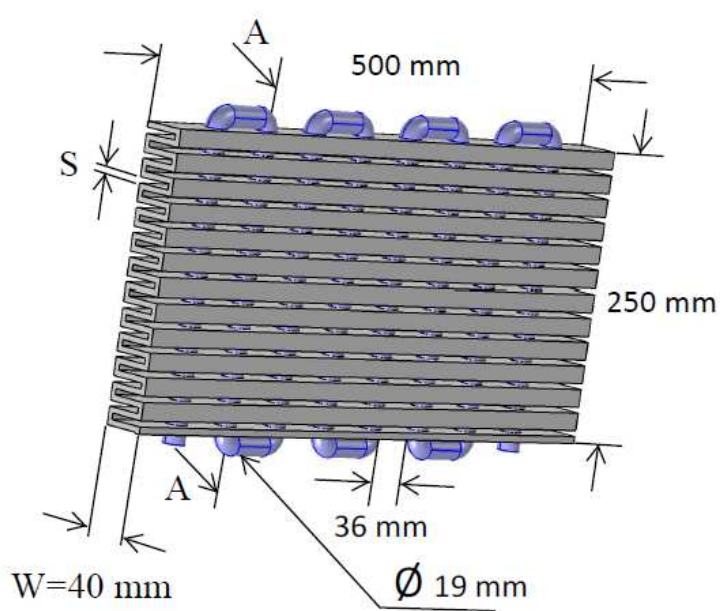

(b)

Figure 1. a. Computational domain, b. the Arrangement of porous block. 


\subsection{Governing equations}

For convection heat transfer, the convection process is governed by the basic conservation principles of mass, momentum, and energy. The continuity and momentum equations that govern the flow in the gas and porous zone are calculated by:

$\nabla . p v=0$

The air is assumed to be a Newtonian fluid and the air flow does not experience any volumetric force. The air dynamic viscosity is a function of temperature which changes with position, the momentum equation is:

$\rho((v \cdot \nabla) v)=\nabla \cdot\left[-p+\mu\left(\nabla v+(\nabla v)^{\mathrm{T}}-\frac{2}{3}(\nabla \cdot v) \mathrm{I}\right)\right]$

In the present analysis, the variation in air thermal conductivity due to temperature change has been considered. With the assumption that the viscous dissipation term is neglected, the energy equation is:

$\rho \mathrm{C}_{\mathrm{p}} \mathrm{v} \cdot \nabla \mathrm{T}=\nabla \cdot(\mathrm{k} \nabla \mathrm{T})$

The governing equations for the pure water with considering of turbulent flow can be written as follows:

Continuity equation:

$\nabla \cdot \rho v=0$

Momentum equation:

$\rho(\mathrm{V} \cdot \nabla) \mathrm{V}=\nabla \cdot\left[-\mathrm{pI}+\left(\mu+\mu_{\mathrm{T}}\right)\left(\nabla \mathrm{V}+(\nabla \mathrm{V})^{\mathrm{T}}\right]+\mathrm{F}\right.$

Turbulent kinetic energy equations:

$\rho(\mathrm{V} . \nabla) k=\nabla \cdot\left[\left(\mu+\frac{\mu_{\mathrm{T}}}{\sigma_{\mathrm{k}}}\right) \nabla k\right]+\mu_{\mathrm{T}}\left[\nabla \mathrm{V}:\left(\nabla \mathrm{V}+(\nabla \mathrm{V})^{\mathrm{T}}\right)\right]-\rho \varepsilon$

Dissipation rate of turbulent kinetic energy:

$\rho(\mathrm{V} \cdot \nabla) \varepsilon=\nabla \cdot\left[\left(\mu+\frac{\mu_{\mathrm{T}}}{\sigma_{\varepsilon}}\right) \nabla \varepsilon\right]+\mathrm{C}_{\mathrm{\varepsilon} 1} \cdot \frac{\varepsilon}{k} \cdot \mu_{\mathrm{T}}\left[\nabla \mathrm{V}:\left(\nabla \mathrm{V}+(\nabla \mathrm{V})^{\mathrm{T}}\right)\right]-\mathrm{C}_{\mathrm{\varepsilon} 2} \cdot \rho \cdot \frac{\varepsilon^{2}}{k}$

Energy equation:

$\rho \mathrm{C}_{\mathrm{p}} \mathrm{v} \cdot \nabla \mathrm{T}=\nabla \cdot(\mathrm{k} \nabla \mathrm{T})$

\subsection{Solution method}

The finite element method (FEM) is used for solving the governing equations and Navier-Stokes equations along with the corresponding boundary conditions by using COMSOL Multiphysics v.5.3. The solution of the governing equations of air was started by solving the continuity and momentum equations with a coarse mesh. The results of the velocity and pressure fields are used as an initial guess for the next step to solve for the velocity and pressure fields with refined mesh. The process of mesh refinement was repeated until a mesh independent solution is reached. The energy equation coupled with the continuity and momentum equations are then solved to reach the result of the velocity, pressure, and temperature fields. Convergence was achieved when the solver iterates until a relative tolerance of $10^{-6}$ is fulfilled. 


\subsection{Boundary Conditions}

The detail parameters that used in calculation such as inlet temperature and velocity of air and water are listed in Table 1, and the main boundary conditions in present study are listed as follows:

Table 1 List of boundary conditions for present study.

\begin{tabular}{|c|c|}
\hline Parameter & Values \\
\hline Air inlet Velocity $\left(\mathbf{V}_{\mathbf{a}}, \mathbf{i n}\right),(\mathrm{m} / \mathrm{s})$ & 0.01 up to $0.035 \mathrm{~m} / \mathrm{s}$ \\
\hline Air inlet Temperature $\left(\mathbf{T}_{\mathbf{a}, \mathbf{i n}}\right),\left({ }^{\circ} \mathrm{c}\right)$ & 25 \\
\hline Water inlet Velocity $\left(\mathbf{V}_{\mathbf{w}, \mathbf{i n}}\right),(\mathrm{m} / \mathrm{s})$ & 50 \\
\hline Water inlet Temperature $\left(\mathbf{T}_{\mathbf{w}, \mathbf{i n}}\right),\left({ }^{\circ} \mathrm{c}\right)$ & 0 \\
\hline Air outlet Pressure $\left(\mathbf{P}_{\mathbf{a}, \mathbf{o}}\right),(\mathrm{Pa})$ & 0 \\
\hline Water outlet Pressure $\left(\mathbf{P}_{\mathbf{w}, \mathbf{o}}\right),(\mathrm{Pa})$ & \\
\hline
\end{tabular}

Figure 2 shows the main boundary conditions with respect to the physical model.

\subsection{Mesh dependence test}

Three different mesh sizes are developed to choose the optimum number of elements to be generated. And the bulk temperature of these meshes is calculated at the outlet flow rate of water to check the sensitivity of the calculations to the grid size. The change in outlet water temperature is negligible as shown in Figure 2 Boundary Conditions

Table 2. Thus, in consideration of both model accuracy and computation time, the grid 2 is appropriate for calculation in this paper.

Figure 2

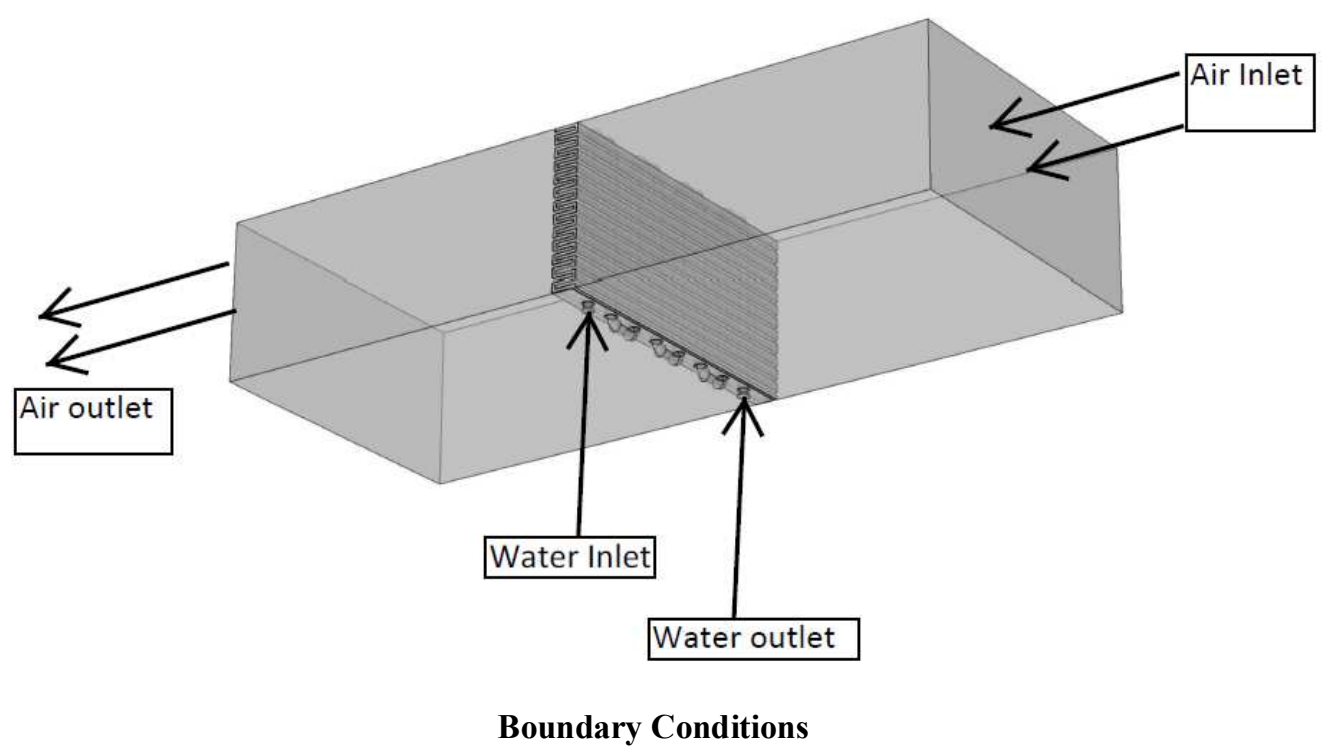

Table 2 Variation of water outlet temperature with number of grid elements.

\begin{tabular}{|c|r|}
\hline No. of Elements & $\mathbf{T}_{\text {water,out }}(\mathbf{k})$ \\
\hline 955723 & 49.8758348 \\
\hline 3451656 & 49.8750861 \\
\hline 13437962 & 49.8879709 \\
\hline
\end{tabular}




\section{RESULTS AND DISCUSSION}

\subsection{Thermal analysis}

The data collected from the numerical model had been processed to evaluate both thermal and hydraulic performance of the wire mesh heat exchangers under steady state conditions for laminar flow of air with velocity range between $0.01 \mathrm{~m} / \mathrm{s}$ up to $0.035 \mathrm{~m} / \mathrm{s}$ and constant conditions of hot water at inlet as water flows with a velocity of $1 \mathrm{~m} / \mathrm{s}$ and inlet temperature of $50{ }^{\circ} \mathrm{C}$. The heat transfer analysis was performed based on the logarithmic mean temperature difference, to evaluate the performance of each of the heat exchangers using the heat transfer rate calculated from the hot water side.

The heat transfer capacity $\dot{\mathrm{Q}} \mathrm{w}$ of the water side can be expressed as:

$\hat{Q}_{\mathrm{w}}=\mathrm{nin}_{\mathrm{w}} * \mathrm{c}_{\mathrm{w}} *\left(\mathrm{~T}_{\mathrm{w}, \mathrm{in}}-\mathrm{T}_{\mathrm{w}, \mathrm{ou}}\right)$

Logarithmic mean temperature difference can then be calculated by:

$\Delta \mathrm{T}_{\mathrm{LM}}=\frac{\left(\mathrm{T}_{\mathrm{w} \text { in }}-\mathrm{T}_{\mathrm{a}, \text { our }}\right)-\left(\mathrm{T}_{\mathrm{w}, \text { out }}-\mathrm{T}_{\mathrm{a}, \mathrm{in}}\right)}{\ln \left(\frac{\left(\mathrm{T}_{\mathrm{w}, \mathrm{in}}-\mathrm{T}_{\mathrm{a} \text { out }}\right)}{\left(\mathrm{T}_{\mathrm{w}, \text { out }}-\mathrm{T}_{\mathrm{a}, \mathrm{in}}\right)}\right)}$

Then the overall heat transfer conductance (AU) can be estimated from:

$\hat{Q}_{\mathrm{w}}=F * \mathrm{~A} * \mathrm{U} * \Delta \mathrm{T}_{\mathrm{LM}}$

where $(\mathrm{F})$ is a correction factor related to the crossflow heat exchanger type, is considered as one, since its value is usually very close to unity.

The total resistance of heat transfer can then be determined from:

$R_{\mathrm{tot}}=\frac{1}{A U}=\frac{1}{A_{\mathrm{in}} h_{\mathrm{in}}}+\frac{\ln \left(\frac{\mathrm{d}_{\mathrm{out}}}{\mathrm{d}_{\mathrm{in}}}\right)}{2 \Pi \mathrm{k}_{\mathrm{p}} \mathrm{l}_{\mathrm{p}}}+\frac{1}{\mathrm{~A}_{\mathrm{o}} \mathrm{h}_{\mathrm{o}}}$

Equation 12 can be rearranged to calculate the convective heat transfer coefficient based on the outside surface area of the water tube as illustrated in equation 13.

$\frac{1}{A_{0} h_{0}}=\frac{1}{A U}-\frac{\ln \left(\frac{d_{\text {out }}}{d_{j n}}\right)}{2 \Pi k_{g} l_{p}}-\frac{1}{A_{\text {in }} h_{\text {in }}}$

Reynold's number is defined based on the hydraulic diameter of the channel as it is shown in, Equation 14.

$\operatorname{Re}_{\mathrm{D}_{\mathrm{h}}}=\frac{\rho_{\text {air }} \mathrm{D}_{\mathrm{h}} \mathrm{V}_{\infty}}{\mu_{\text {air }}}$

The internal convection heat transfer coefficient on the waterside hin is calculated from Gnielinski formula. The second term on the righthand side of the equation 13 is the conduction heat transfer resistance of the copper pipe wall which can be neglected as it is thin tube having high thermal conductivity. 
Figure 3 shows that, the overall heat transfer coefficient increases with the increase in the average air velocity at flow conditions of $50{ }^{\circ} \mathrm{C}$, and $1 \mathrm{~m} / \mathrm{s}$ for the hot water. It is obvious that there is a significant enhancement in heat transfer between the finned modules and the bare one due to the great increase in the surface area for the wire meshed heat exchanger. Among the six spacings, the $3 \mathrm{~mm}$ showed the best thermal performance

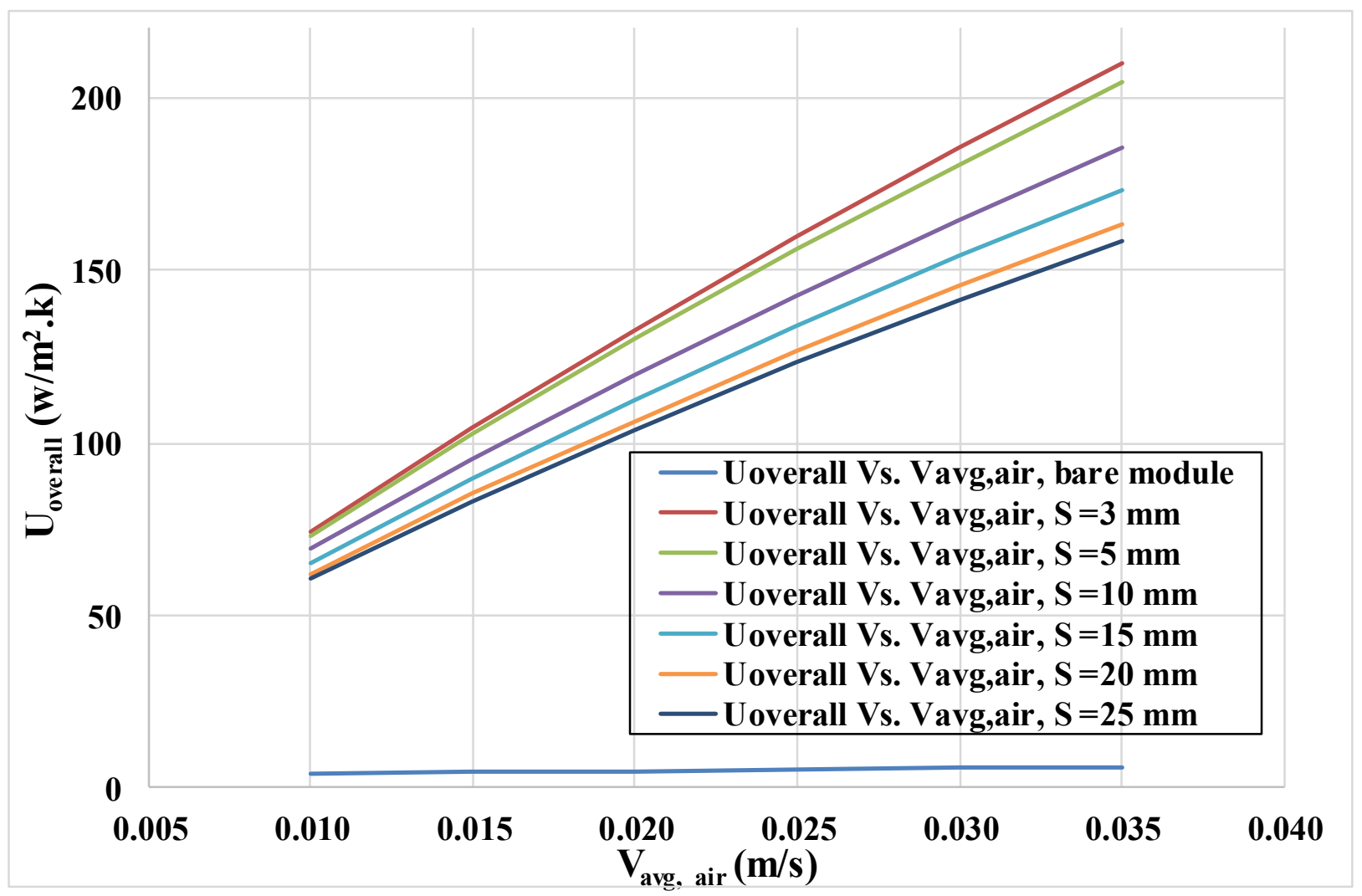

Figure 3 Overall heat transfer coefficient variation with average air velocity.

Figure 4 illustrates the variation of the air temperature drop with average air velocity for the different spacings. As air velocity increases the temperature difference decreases due to the higher disturbances occur at greater air velocities which results in more active convection heat transfer. Also, it can be shown from the figure for the same air velocity as the layer-to-layer spacing decreases the air temperature drop increases which refers to the improvement of the thermal performance as the spacing decreases. 


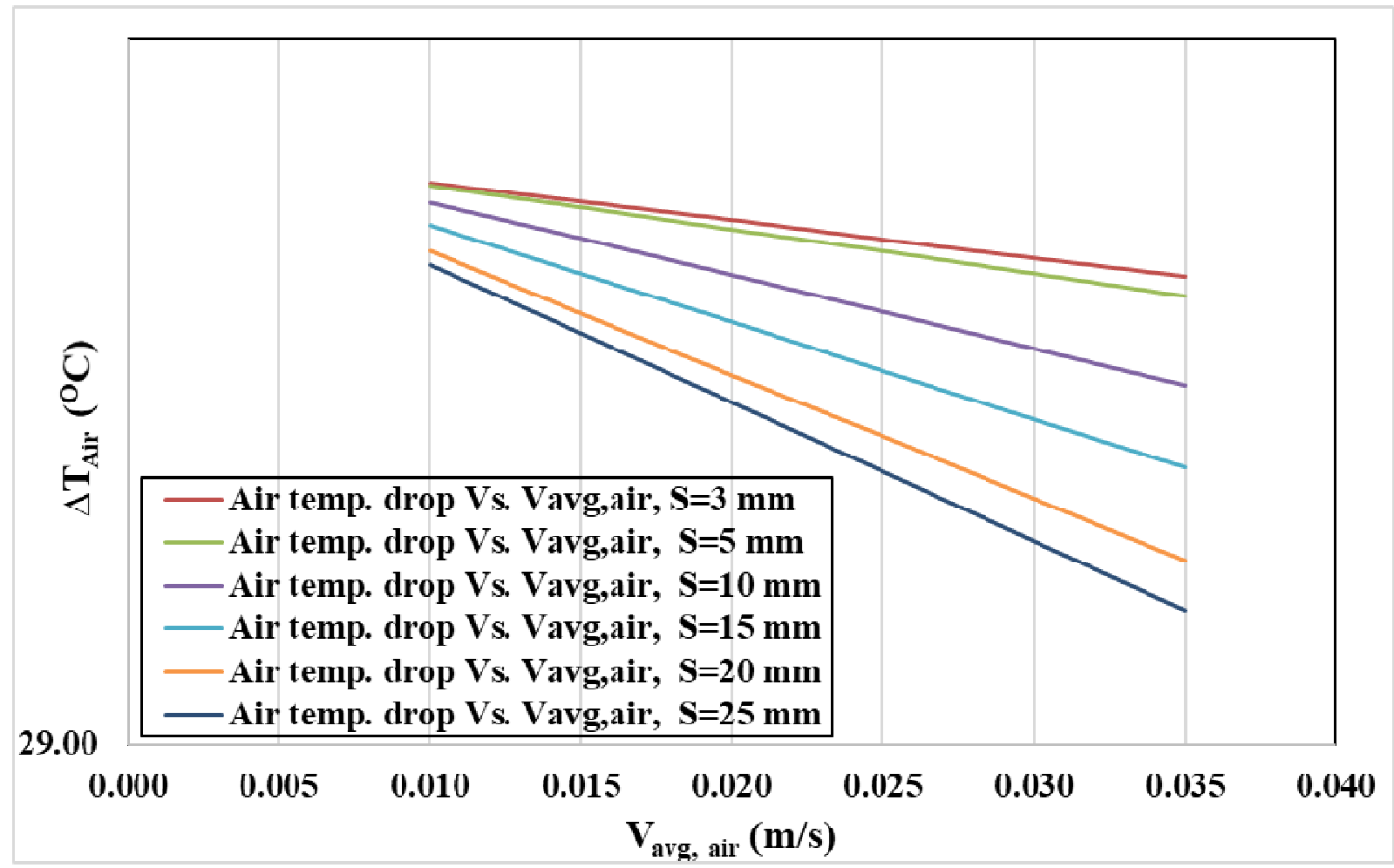

Figure 4 Variation of the air temperature drops with average air velocity.

Figure 5 shows the variation of heat rate enhancement ratio with the average air velocity for the $3 \mathrm{~mm}$ spaced module and the $25 \mathrm{~mm}$ spaced module. The difference in enhancement does not change dramatically between the 2 spaces as the average velocity range is too low. Therefore, the study recommends choosing the $25 \mathrm{~mm}$ spaced module as there is no considerable difference between the 2 spaces for the thermal performance wise as it is less difficult to solve and simulate.

\subsection{Pressure drop analysis}

For hydraulic performance evaluation air-side pressure drop was calculated for the six heat exchanger modules compared with the bare one. Figure 6 shows the variation of the pressure drop across various modules with the average air velocity. The pressure drop of the wire mesh heat exchanger increases significantly (450 times) compared with bare module as the friction drag increases due to insertion of corrugated wire mesh to the heat exchanger. Results illustrate that as the layer-to-layer spacing increases the pressure drop increases. Such phenomena happened because the percentage of the air mass flow in the vertical direction is much higher than the horizontal direction as the air flow is laminar. The vertical flow percentage increase with decreasing the layer-to-layer spacing.it was found that for the $3 \mathrm{~mm}$ spaced module, the vertical flow percentage exceeds $90 \%$ of the total air mass flow rate which cause the pressure drop to decrease significantly. Therefore, for pressure drop wise the $3 \mathrm{~mm}$ spaced module is recommended as it achieves the best hydraulic performance. 


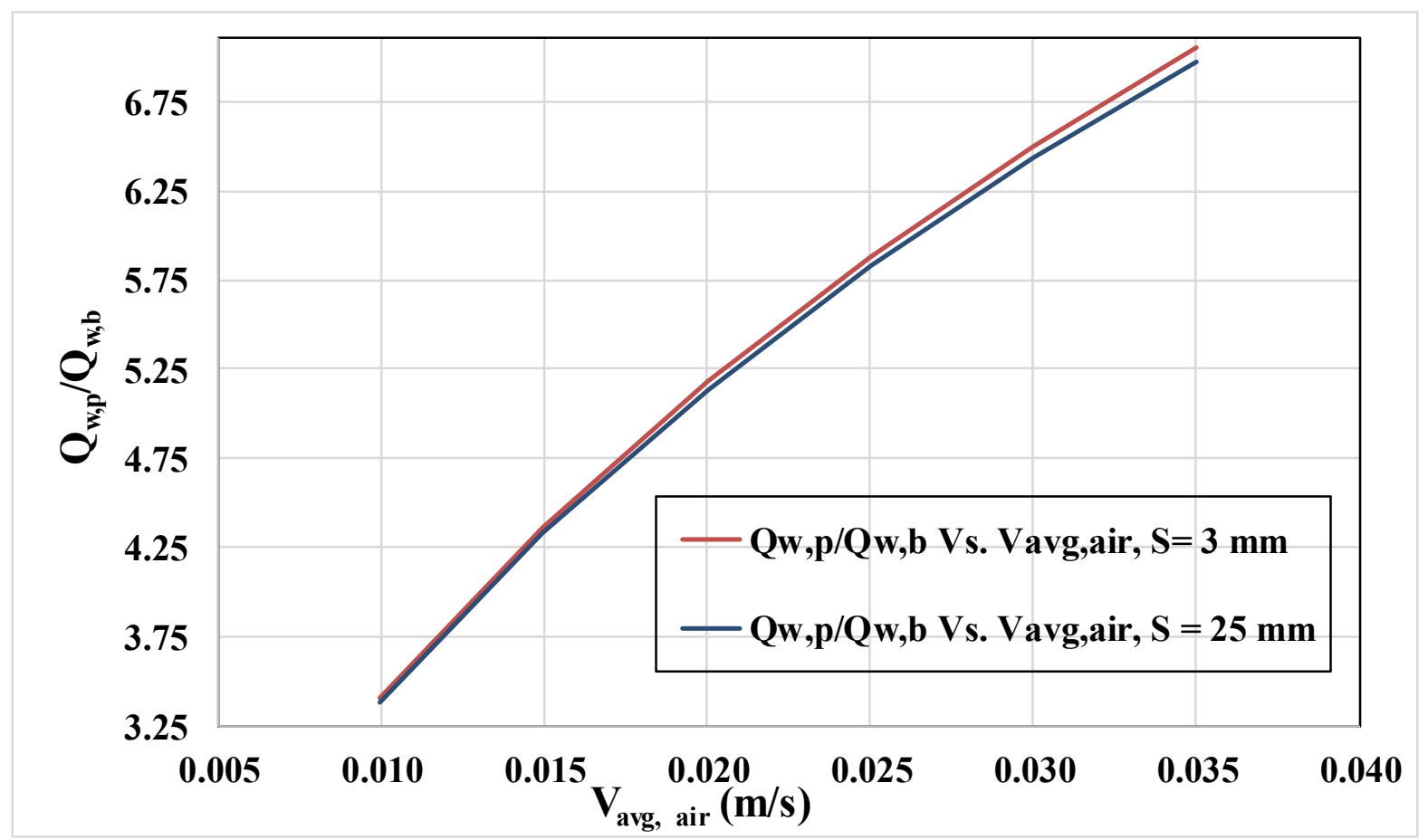

Figure 5 the variation of heat rate enhancement ratio with the average air velocity.

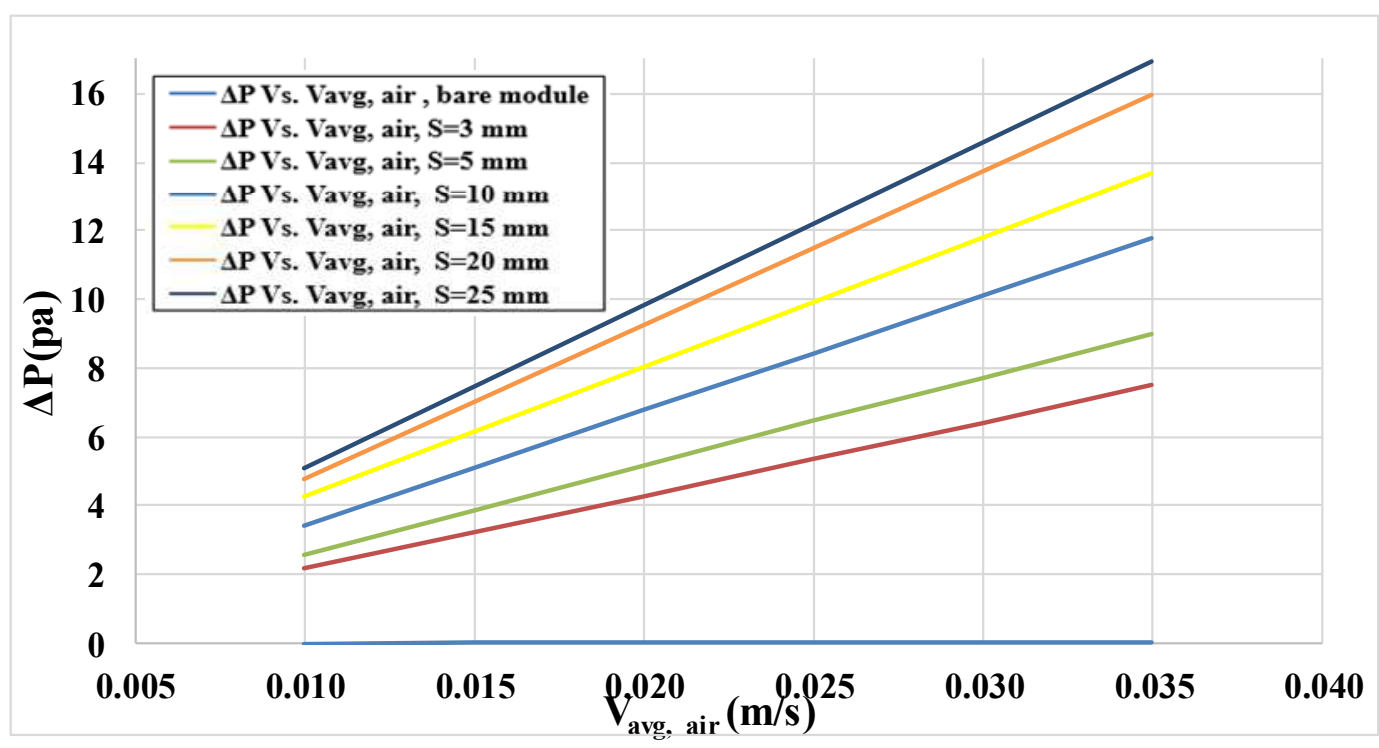

Figure 6 Air pressure drop variation with the average air velocity.

\subsection{Combined performance analysis}

Each of the thermal and hydraulic analysis recommends different spaced module. Therefore, the combination of those performance is developed to recognize the best wire mesh heat exchanger by showing the variation of the ratio of heat transfer rate per unit pumping power with Reynold's 
number as shown in Figure 7. as the average air velocity increases, the pumping power increases. The pumping power is calculated as shown in Equation 15.

Pumping power $=\dot{V}_{\text {air }} \Delta \mathrm{P}$

Where, $\dot{V}_{\text {air }}$, air volume flow rate, is calculated from average air velocity as shown in Equation 16.

$\dot{V}_{\text {air }}=V_{\text {avgair }} \cdot A_{a}$

On the other hand, the heat transfer rate per unit pumping power decreases. The $3 \mathrm{~mm}$ spaced module appeared to have the best combined performance among the six modules.

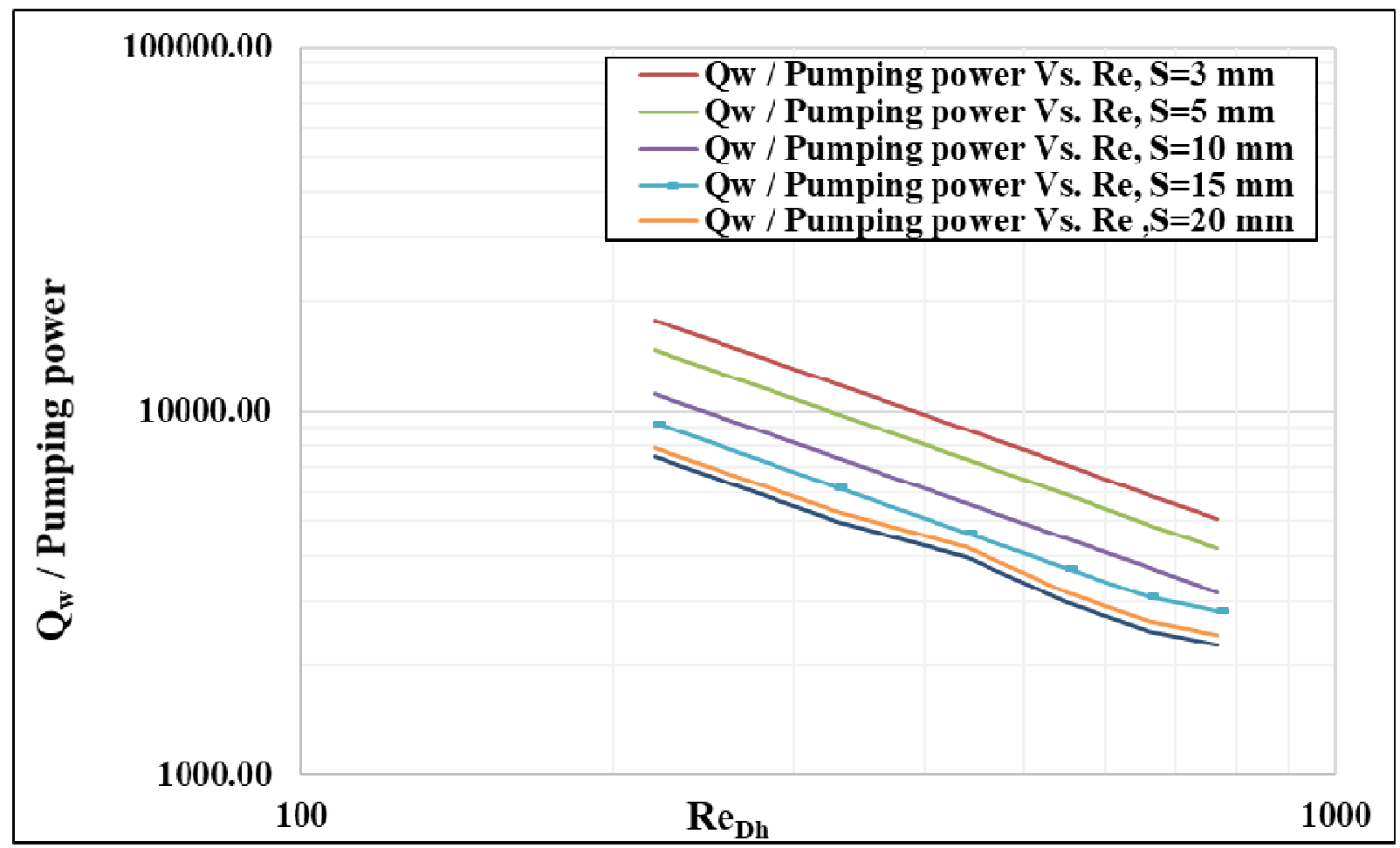

Figure 7 the variation of the ratio of heat transfer rate per unit pumping power with Reynold's number.

\section{CONCLUSION}

In this paper, the heat transfer and pressure drop performance of the single row water to-air cross flow woven wire mesh heat exchanger were theoretically investigated. The heat exchanger consists of eight equally spaced copper pipes. A corrugated copper wire mesh is fitted to the heat exchanger pipe. Six modules were simulated of 3, 5, $10,15,20$ and $25 \mathrm{~mm}$ layer-to-layer spacing with porosity of 0.75 and permeability of $10^{-10}$. The steady state forced convection experiments were conducted and the conclusions obtained as follow:

1) A comparison of overall heat transfer coefficient is done between different heat exchanger modules. Maximum average increase of 25 times in overall heat transfer coefficient is achieved by the $3 \mathrm{~mm}$ spaced finned module compared with the bare model while the difference in the thermal enhancement between the $3 \mathrm{~mm}$ and $25 \mathrm{~mm}$ spaced module is not considerable. Therefore, the $25 \mathrm{~mm}$ spaced module is recommended as it is much less difficult to deal with numerically. 
2) A comparison of pressure drop is done between different heat exchanger modules. Results showed the pressure drop for the wire mesh heat exchanger increases 450 times compared with the bare module. The $3 \mathrm{~mm}$ spaced module showed to have the lower pressure drop among the six modules. Therefore, the $3 \mathrm{~mm}$ spaced module is recommended as it has the best hydraulic performance (The lowest pressure drop).

3) A comparison of the ratio of heat transfer rate per unit pumping power is done between the different heat exchanger module to evaluate the combined performance. Results showed that, the $3 \mathrm{~mm}$ spaced module has the best combined performance among the group.

\section{REFERENCE}

1. Angirasa, D. (2002). Experimental investigation of forced convection heat transfer augmentation with metallic fibrous materials. International Journal of Heat and Mass Transfer, 45(4), 919-922.

2. Dogan, M., \& Sivrioglu, M. (2012). Experimental and numerical investigation of clearance gap effects on laminar mixed convection heat transfer from fin array in a horizontal channel-A conjugate analysis. Applied Thermal Engineering, 40, 102-113.

3. Dong, J., Chen, J., Zhang, W., \& Hu, J. (2010). Experimental and numerical investigation of thermal-hydraulic performance in wavy fin-and-flat tube heat exchangers. Applied Thermal Engineering, 30(11-12), 1377-1386.

4. Dyga, R., \& Płaczek, M. (2010). Efficiency of heat transfer in heat exchangers with wire mesh packing. International Journal of Heat and Mass Transfer, 53(23-24), 5499-5508.

5. El Maakoul, A., El Metoui, M., Abdellah, A. B., Saadeddine, S., \& Meziane, M. (2017). Numerical investigation of thermohydraulic performance of air to water double-pipe heat exchanger with helical fins. Applied Thermal Engineering, 127, 127-139.

6. Fugmann, H., Tahir, A. J., \& Schnabel, L. (2015). Woven Wire Gas-To-Liquid Heat Exchanger. Paper presented at the World Congress on Mechanical, Chemical and Material Engineering; Avestia Publishing, International ASET Inc.: Ottawa, ON, Canada.

7. Huisseune, H., T'Joen, C., Brodeoux, P., Debaets, S., \& De Paepe, M. (2010). Thermal hydraulic study of a single row heat exchanger with helically finned tubes. Journal of heat transfer, 132(6).

8. Hwang, J.-J., Hwang, G.-J., Yeh, R.-H., \& Chao, C.-H. (2002). Measurement of interstitial convective heat transfer and frictional drag for flow across metal foams. J. Heat Transfer, 124(1), 120-129.

9. Kamath, P. M., Balaji, C., \& Venkateshan, S. (2013). Convection heat transfer from aluminium and copper foams in a vertical channel-An experimental study. International Journal of Thermal Sciences, 64, 1-10.

10. Kewalramani, G. V., Hedau, G., Saha, S. K., \& Agrawal, A. (2019). Study of laminar single phase frictional factor and Nusselt number in In-line micro pin-fin heat sink for electronic cooling applications. International Journal of Heat and Mass Transfer, 138, 796-808.

11. Lu, W., Zhao, C., \& Tassou, S. (2006). Thermal analysis on metal-foam filled heat exchangers. Part I: Metal-foam filled pipes. International Journal of Heat and Mass Transfer, 49(15-16), 2751-2761.

12. Mahajan, R. L. (2001). Transport phenomena in high porosity metal foams. Ph. D. thesis, University of Colorado,

13. Mancin, S., Zilio, C., Diani, A., \& Rossetto, L. (2012). Experimental air heat transfer and pressure drop through copper foams. Experimental thermal and fluid science, 36, 224232.

14. Wang, Y., Dong, T., Cao, W., Peng, P., \& Jiang, F. (2020). Experimental investigation of the laminar flow and heat transfer performance of a harmonica tube with or without minifins. Applied Thermal Engineering, 164, 114502. 